\title{
A STUDY OF NON ALCOHOLIC FATTY LIVER DISEASE IN PATIENTS WITH METABOLIC SYNDROME
}

D. Vasundhara Devi, M. Madhu Latha, A. Sumapreethi, S. S. B. Sharma, M. Priyanka

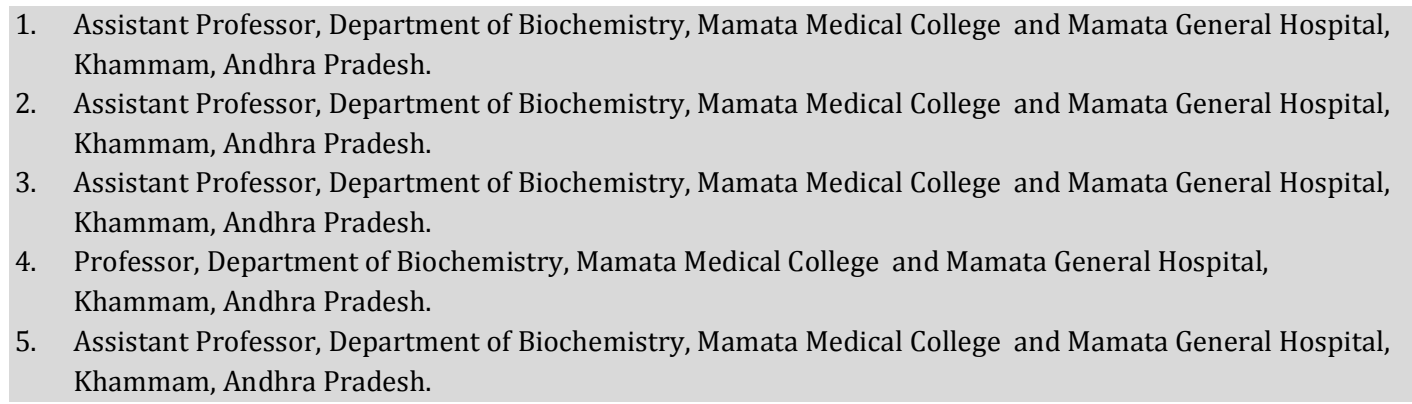

\section{CORRESPONDING AUTHOR}

Dr. D. Vasundhara Devi, M.D.,

Assistant Professor,

Department of Biochemistry,

Mamata Medical College,

Khammam, 507002.

E-mail: vasundhara777@yahoo.com

Ph: 00919908824225

ABSTRACT: This study was conducted to know the relation of non- alcoholic fatty liver disease (non-alcoholic steatohepatitis \& cirrhosis) with metabolic syndrome. MATERIAL AND METHODS: 60 cases were selected. Out of them 30 were non-alcoholic steatohepatitis and 30 cirrhosis along with 30 healthy controls. Parameters of metabolic syndrome and liver function which are waist circumference, blood pressure, fasting plasma glucose, total triglycerides, high density lipo- protein cholesterol, total bilirubin, alanine amino transferase, alkaline phosphotase, total proteins and albumin were measured. STATISTICAL ANALYSIS: All values were expressed as mean \pm SD. The results obtained were analyzed statistically using the unpaired student ' $t$ 'test to evaluate the significance of differences between the mean values. RESULTS: The values of waist circumference, fasting plasma glucose, systolic blood pressure, total triglycerides, total bilirubin, alanine-amino-transferase and alkaline phosphotase were raised in non-alcoholic steatohepatitis and cirrhosis patients. The level of high density lipoprotein cholesterol was decreased in non-alcoholic steatohepatitis and cirrhosis patients. The level of albumin was decreased in cirrhosis patients. CONCLUSION: On the basis of our results it may be concluded that metabolic syndrome causes nonalcoholic fatty liver disease.

KEYWORDS: metabolic syndrome, non- alcoholic fatty liver disease, hepatic steatosis, nonalcoholic steatohepatitis, cirrhosis

INTRODUCTION: Non-alcoholic fatty liver disease (NAFLD) is the occurrence of fatty liver in people who have no history of alcohol consumption. NAFLD includes hepatic steatosis (accumulation of fat in the hepatocytes), non-alcoholic steatohepatitis and cirrhosis. Clark et al stated that when inflammation occurs to hepatic steatosis the condition was then called nonalcoholic steatohepatitis (NASH) which is a clinical form of non-alcoholic fatty liver disease and a major cause of cirrhosis of the liver(1). Cirrhosis is a consequence of chronic liver disease 
characterized by replacement of liver tissue by fibrosis, scar tissue and regenerative nodule leading to loss of liver function. Complications of cirrhosis are ascitis, esophageal varices and hepatic encephalopathy that can cause coma and death. Different studies have revealed that cirrhosis is generally irreversible resulting in liver failure or liver related death in approximately one third of cases. ${ }^{(2,3)}$

The incidence of non-alcoholic fatty liver disease has been in upward trend in the people in all parts of the world including India. According to different studies the prevalence of NAFLD ranges from 9 to $36.9 \%$ of the population in different parts of the world. $(4,5,6)$ Epidemiological studies suggest prevalence of NAFLD is around $9 \%$ to $32 \%$ of general population in India with higher prevalence in those with overweight or obesity and those with diabetes or prediabetes. ${ }^{7)}$ NASH may be present in about $1 / 3$ of NAFLD cases, while $20-25 \%$ of NASH cases could progress to cirrhosis.

There are some studies at different geographical areas which have proposed strongly that NAFLD is associated with metabolic syndrome. $(8,9,10,11)$ Metabolic syndrome is associated with insulin resistance. Insulin resistance is a physiological condition where the natural hormone insulin becomes less effective at lowering blood sugars. Insulin resistance increases free fatty acids and triglycerides in liver and serum. Current concepts suggest that the development of NASH is a two-hit process. With the initial hit macrovesicular steatosis results from insulin resistance and subsequent hyperinsulinemia which leads to alterations in the hepatic pathways of synthesis of fatty acids and ultimately to accumulation of lipids in the hepatocytes. These changes make the liver susceptible to a second hit resulting in inflammatory response and progress to liver damage. Oxidative stress mainly as a consequence of mitochondrial dysfunction and proinflammatory cytokines such as TNF- $\infty$ are thought to play a central role in the progression from simple steatosis to steatohepatitis and cirrhosis and these may be potential causes for second hit phenomenon(12).

Sedentary lifestyle, a low physical activity and excess caloric intake(13) increase adipose tissue (predominantly central), reduce HDL cholesterol and is a trend towards increased triglycerides, blood pressure, and glucose causing metabolic syndrome thereby resulting in liver damage. It is observed that individuals who watch television or videos or sit before computers for more than four hours daily have a twofold increased risk of metabolic syndrome due to low physical activity.

Although much progress has been made more studies are needed to clearly define the progression of NAFLD from metabolic syndrome. Aim of the present study was to assess the parameters of metabolic syndrome and liver function in NAFLD (NASH \& cirrhosis) to know the relation between metabolic syndrome and NAFLD.

\section{MATERIAL AND METHODS: STUDY GROUP:}

The present study was carried out during the years 2009 to 2012 in the Department of Biochemistry, Mamata Medical College and General Hospital, Khammam, Andhra Pradesh. A total of 60 cases of Non- alcoholic fatty liver disease were selected in this study group after obtaining their consent. Out of these 30 were non-alcoholic steatohepatitis and 30 were cirrhosis cases in the age group of 35 to 65 years.

Diagnosis of cases was based on:

a. History: Non-alcoholics

b. Biochemical: abnormal liver function tests 
c. Radiological: liver ultrasound showing steatosis was used to exclude gallstone problems (cholelithiasis). Ultrasound was used in the evaluation of cirrhosis. It showed a small and nodular liver in advanced cirrhosis along with increased echogenicity with irregular appearing areas.

d. Liver biopsy: liver biopsy (tissue examination) was conducted to distinguish NASH from other forms of liver disease and was used to assess the severity of the inflammation and resultant fibrosis.

e. Cases with three or more of the five markers of metabolic syndrome as per NCEP ATP III guidelines were included in this study. As per the Updated NCEP ATP III $(14,15,16)$ guidelines the markers of metabolic syndrome are:1.Elevated waist circumference: mengreater than 40 inches, women-greater than 35 inches; 2.Elevated triglycerides: equal to or greater than $150 \mathrm{mg} / \mathrm{dl}$; 3.Reduced HDL (good) cholesterol: men-less than $40 \mathrm{mg} / \mathrm{dl}$, women-less than $50 \mathrm{mg} / \mathrm{dl}$; 4 .Elevated blood pressure: equal to or greater than 130/85 mm $\mathrm{Hg}$; and 5.Elevated fasting glucose: equal to or greater than $100 \mathrm{mg} / \mathrm{dl}$.

Exclusion criteria of cases: 1.alcoholics, 2.subjects on medication for HTN,3.subjects not having metabolic syndrome

Controls: 30 , sex and age matched healthy persons, were recruited as controls.

Sample collection:

$5 \mathrm{ml}$ venous blood was taken from each subject and divided into two parts. $1 \mathrm{ml}$ blood was transferred to an EDTA containing test tube and then centrifuged. Plasma was separated and used to determine fasting plasma glucose (FPG).Remaining $4 \mathrm{ml}$ of venous blood was also centrifuged at $3000 \mathrm{rmp}$ for 15 minutes. Serum was separated and used for the estimation of total triglycerides (TAG), high density lipoprotein cholesterol (HDL-C) , total bilirubin, alanineamino-transferase( ALT) , alkaline phosphatase (ALP), total proteins and albumin .

Biochemical estimation:

FPG was determined by using the Glucose Oxidase \Peroxidase (GOD \POD) method.(17) TAG was determined by using Enzymatic method (Glycero Phosphate Oxidase). HDL-C was determined by using Enzymatic method(Poly Ethylene Glycol/Cholesterol Oxidase method).Total bilirubin was estimated by using the Modified Jendrassik \& Grof's method.(18)ALT was estimated by using the Modified International Federation of Clinical Chemistry(Mod. IFCC) method.ALP was estimated using the Para Nitro Phenyl Phosphate Kinetic method. Total protein was determined by using the Biuret method. Albumin was determined by using the Bromocresol Green (BCG) Dye Binding method.

STATISTICAL ANALYSIS: All values were expressed as mean \pm SD. The results obtained were analyzed statistically using the unpaired student't'test to evaluate the significance of differences between the mean values. P values $<0.05$ were considered as significant and $<0.001$ as highly significant.

RESULTS: Results of the parameters of metabolic syndrome and liver function in NASH and cirrhosis comparing with healthy controls are in the tables $1 \& 2$. Table 1 contains the mean, SD and $\mathrm{p}$ value of waist circumference, FPG, systolic blood pressure, diastolic blood pressure, TAG, and HDL-C of NASH, cirrhosis and controls. Table 2 contains the mean, SD and p value of total bilirubin, ALT, ALP, total proteins, albumin and globulins of NASH, cirrhosis and controls.

From the results of our study the following observations were made: 


\section{PARAMETERS OF METABOLIC SYNDROME:}

1. The mean levels of waist circumference, FPG, systolic blood pressure and TAG were increased in NASH and cirrhosis cases when compared with controls and the mean difference was statistically significant.

2. The mean HDL-C level was decreased in NASH and cirrhosis cases when compared with controls and the mean difference was statistically significant.

3. The mean diastolic blood pressure level was increased in both NASH and cirrhosis cases when compared with controls. The mean difference was significant between NASH and controls but not significant between cirrhosis and controls.

\section{PARAMETERS OF LIVER FUNCTION:}

1. The mean levels of total bilirubin, ALT, ALP, and globulins were increased in the cases of NASH and cirrhosis. The mean difference was statistically significant when compared with controls.

2. The mean levels of total proteins and albumin were decreased in NASH and cirrhosis cases when compared with controls and the mean difference was statistically significant except total proteins between NASH group and control group.

DISCUSSION: Amarapurkar et al in their population based study in 2007 on prevalence of NAFLD stated that there was an increase in incidence of NAFLD in India.(19) One study reports that approximately $23 \%$ of the United States population suffers from non-alcoholic fatty liver and continues to trend upward.(20)

Abdominal obesity or clinically known as central obesity is the accumulation of abdominal fat resulting in an increase in waist size. The severity of central obesity is determined by taking waist measurement. Our results showed that the measurement of waist circumference was highly significantly raised $(\mathrm{p}<0.001)$ in the patients with NASH and cirrhosis than control group. Central obesity is common among NAFLD patients and reflects an increase in visceral adipose tissue which appears to be particularly resistant to the effects of insulin(21). Central obesity is associated with a higher risk of hypertension, insulin resistance and diabetes mellitus type 2.

Several reports indicated the relation of NAFLD to diabetes mellitus. $(22,11,23)$ Our results also showed highly significantly raised $(\mathrm{p}<0.001)$ level of FPG in the patients of NASH as well as cirrhosis than controls. Insulin resistance prevents the body from converting glucose into glycogen which in turn makes it difficult or impossible to remove excess glucose from the blood. Younossi et al. reported that patients with NAFLD and diabetes mellitus and associated with insulin resistance had more aggressive disease with a higher percentage of cirrhosis and higher odds of liver cell necrosis compared with those without diabetes.(24)

The levels of both systolic blood pressure and diastolic blood pressure increased in this study in the patients when compared with controls. These are in accordance with earlier findings.(12,1) High blood pressure damages the entire complex circulatory system. Therefore managing the blood pressure is an important part of prolonging the health of the organs. The 
risk increases even more if we have high blood pressure along with other risk factors such as overweight or obesity, high cholesterol, diabetes and physical inactivity .

In our study we observed highly significantly raised $(\mathrm{p}<0.001)$ level of TAG in patients when compared with controls. Assy et al in their study reported that NAFLD was found in up to $50 \%$ of patients with hypertriglyceridemia.(25) Insulin resistance increases free fatty acids and triglycerides in liver and serum causing hepatic steatosis and progress to NASH and cirrhosis. Obesity, diabetes mellitus and insulin resistance increase triglyceride levels.

The level of HDL-C was highly significantly decreased $(\mathrm{p}<0.001)$ in our study in NASH and cirrhosis than controls. Various previous studies also revealed that NAFLD was related to dislipidemia. $(21,22,26,27)$ HDL particles transport cholesterol back to the liver for excretion or reutilization. HDL-C level decreased in metabolic syndrome due to a low physical activity

Bilirubin is a breakdown product of heme (a part of hemoglobin in red blood cells).The results of the present study showed that the patients with NASH and cirrhosis had increased total bilirubin when compared with controls. As per our observations the level of ALT was highly significantly raised $(\mathrm{p}<0.001)$ in patients than controls.ALT is an enzyme present in hepatocytes. When cell is damaged, it leaks this enzyme into the blood. The level of ALT rises with the damage liver cell. The level of ALP an enzyme in the cells lining the biliary ducts of the liver was also raised in patients when compared with controls. ALP levels in plasma rise with intrahepatic cholestasis or infiltrative diseases of the liver.

The levels of proteins and albumin were highly significantly decreased $(\mathrm{p}<0.001)$ in patients with cirrhosis. This finding was in accordance with the finding of Melvin Jay Schwartz, ${ }^{28)}$ who reported that hypoalbuminemia occurred in cirrhosis. Albumin which is the main constituent of total protein is produced in the liver. The levels of albumin fall as the synthetic function of the liver declines with cirrhosis.

In the present study, it was observed that the parameters of metabolic syndrome became abnormal. The abnormal parameters of metabolic syndrome cause liver damage. Free fatty acids and triglycerides in liver and serum increased in the patients of metabolic syndrome and caused fatty liver which progress to NASH and cirrhosis. It was observed that the parameters of the liver function were abnormal in the patients of NASH and cirrhosis.

Thus it may be concluded that metabolic syndrome leads to NAFLD resulting in liver failure or liver-related death. The results were consistent with other studies. $(8,9,10,11)$ There are various strategies to prevent the development of metabolic syndrome such as increased physical activity ( walking 30 minutes every day), ${ }^{(29)}$ a healthy and reduced calorie diet.(30)

\section{REFERENCES:}

1. Clark JM, Diehl AM. Nonalcoholic fatty liver disease: an under-recognized cause of cryptogenic cirrhosis. JAMA 2003; 289: 3000-4.

2. Ratziu V, Bonyhay L, Di Martino V, Charlotte F, Cavallaro L, Sayegh-Tainturier MH, et al. Survival, liver failure, and hepatocellular carcinoma in obesity-related cryptogenic cirrhosis. Hepatology. 2002; 35:1485-93.

3. Hui JM, Kench JG, Chitturi S, Sud A, Farrell GC, Byth K, et al. Long-term outcomes of cirrhosis in nonalcoholic steatohepatitis compared with hepatitis C. Hepatology. 2003;38:420-7.

4. Omagari K, Kadokawa Y, Masuda J, Egawa I, Sawa T, Hazama H, et al. Fatty liver in nonalcoholic non overweight Japanese adults: incidence and clinical characteristics. J Gastroenterol Hepatol year-2002: 1098-1105. 
5. Hilden M, Christoffersen P, Juhl E, Dalgaard JB (1977). Liver histology in a normal population examinations of 503 consecutive fatal traffic casualties. Scand J Gastroenterol 12 (5): 593-7.

6. Shen L, Fan JG, Shao Y, Zeng MD, Wang JR, Luo GH, et al. (2003). Prevalence of nonalcoholic fatty liver among administrative officers in Shanghai: an epidemiological survey. World J Gastroenterol 9: 1106-10.

7. Duseja A. Nonalcoholic fatty liver disease in India - a lot done, yet more required! Indian J Gastroenterol. 2010 Nov; 29(6):217-25.

8. Marchesini G, Brizi M, Bianchi G, et al. Nonalcoholic fatty liver disease: a feature of the metabolic syndrome. Diabetes. 2001; 50: 1844-1850.

9. Cortez-Pinto H, Camilo ME, Baptista A, De Oliveira AG, De Moura MC. Non-alcoholic fatty liver: another feature of the metabolic syndrome? Clin. Nutr. 1999; 18:353-358.

10. Ratziu V, Giral P, Charlotte F, Bruckert E, Thibault V, Theodorou I, et al. Liver fibrosis in overweight patients. Gastroenterology 2000;118:1117-23.

11. Wanless IR, Lentz JS. Fatty liver hepatitis (steatohepatitis) and obesity: an autopsy study with analysis of risk factors. Hepatology. 1990;12:1106-1110.

12. Adams LA, Angulo P (2006). Treatment of non-alcoholic fatty liver disease, Postgrad Med J 82 (967): 315-22.

13. Katzmaryk, Peter T, Leon, Arthur S, Wilmore, Jack H, Skinner, James S, Rao D. C, Rankinen, Tuomo, Bouchard, Claude (October 2003). Targeting the Metabolic Syndrome with Exercise: Evidence from the HERITAGE Family Study. Med. Sci. Sports Exerc 35 (10): 1703-1709.Retrieved 2007-06-24.

14. Expert Panel On Detection, Evaluation, And Treatment Of High Blood Cholesterol In Adults (May 2001) Executive Summary of the Third Report of the National Cholesterol Education Program (NCEP) Expert Panel on Detection, Evaluation, and Treatment of High Blood Cholesterol in Adults (Adult Treatment Panel III). JAMA: the Journal of the American Medical Association 285 (19): 2486-97.

15. Grundy SM, Brewer HB, Cleeman JI, Smith SC, Lenfant D, for the Conference Participants. Definition of metabolic syndrome: report of the National Heart, Lung, and Blood Institute/American Heart Association conference on scientific issues related to definition. Circulation. 2004;109:433-438.

16. Grundy SM, Cleeman JI, Daniels SR, Donato KA, Eckel RH, Franklin BA, et al. Diagnosis and Management of the Metabolic Syndrome: An American Heart Association/National Heart, Lung, and Blood Institute Scientific Statement. Circulation 2005, 112:2735-2752: originally published online September 12, 2005.

17. Trinder P Estimation of blood glucose by GOD-POD method. Ann Clin Bio Chem 1969: 6: 24.

18. Tietz.NW. Fundamentals of Clinical Chemistry. Published by WB Saunders Company. 1986. page 1388-1390.

19. Amarapurkar D, Kamani P, Patel N, Gupte P, Kumar P, Agal S,et al.Prevalence of nonalcoholic fatty liver disease: population based study. 2007 Jul-Sep;6(3):161-3.

20. Ioannou GN, Boyko EJ, Lee SP. (2006).The prevalence and predictors of elevated serum aminotransferase activity in the United States in 1999-2002. Am J Gastroenterol 101 (1): 76-82.

21. Chitturi S, Farrell GC, George J. Non-alcoholic steatohepatitis in the Asia-Pacific region: future shock? J Gastroenterol Hepatol 2004;19: 368-74. 
22. Bacon BR,Farahvash MJ, Janney CG, Neuschwander-Tetri BA. Nonalcoholic steatohepatitis: an expanded clinical entity. Gastroenterology 1994;107:1103-9.

23. Powell EE, Cooksley WG, Hanson R, Searle J, Halliday JW, Powell LW. The natural history of nonalcoholic steatohepatitis: a follow-up study of forty-two patients for up to 21 years.Hepatology. 1990;11:74-80.

24. Younossi ZM, Gramlich T, Matteoni CA, et al. Nonalcoholic fatty liver disease in patients with type 2 diabetes. Clin Gastroenterol Hepatol 2004; 2:262-5.

25. Assy N, Kaita K, Mymin D, Levy C, Rosser B, Minuk G. Fatty infiltration of liver in hyperlipidemic patients. Dig Dis Sci 2000; 45:1929-34.

26. De Fronzo RA, Ferrannini E: Insulin resistance. A multifaceted syndrome responsible for NIDDM, obesity, hypertension, dyslipidemia, and atherosclerotic cardiovascular disease. Diabetes Care 1991; 14(3):173-194.

27. Diehl AM, Goodman Z, Ishak KG. Alcohol like liver disease in nonalcoholics: a clinical and histologic comparison with alcohol-induced liver injury. Gastroenterology. 1988; 95:1056-1062.

28. Melvin Jay Schwartz Steatorrhea and hypoalbuminemia in cirrhosis with ascites Digestive Diseases and Sciences

29. Lakka TA, Laaksonen DE (2007).Physical activity in prevention and treatment of the metabolic syndrome. Applied physiology, nutrition, and metabolism-Physiologie appliquée, nutrition et métabolisme 32 (1): 76-88.

30. Feldeisen SE, Tucker KL (2007). Nutritional strategies in the prevention and treatment of metabolic syndrome. Appl Physiol Nutr Metab 32 (1): 46-60.

31. TABLE 1: Parametres of metabolic syndrome in the patients of NASH and cirrhosis compared with healthy controls.

32. TABLE 2: Parameters of liver function in the patients of NASH and cirrhosis compared with healthy controls.

TABLE 1: Parametres of metabolic syndrome in the patients of NASH and cirrhosis compared with healthy controls.

\begin{tabular}{|l|l|l|l|l|l|}
\hline & $\begin{array}{l}\text { Controls } \\
\text { mean } \pm \text { S.D }\end{array}$ & $\begin{array}{l}\text { NASH } \\
\text { mean } \pm \text { S.D }\end{array}$ & $\begin{array}{l}\text { P value } \\
\text { (controls vs } \\
\text { NASH) }\end{array}$ & $\begin{array}{l}\text { Cirrhosis } \\
\text { mean } \pm \text { S.D }\end{array}$ & $\begin{array}{l}\text { P value } \\
\text { (controls vs } \\
\text { cirrhosis })\end{array}$ \\
\hline WC(inches) & $33.4 \pm 4.3$ & $41.8 \pm 2.72$ & $\mathrm{P}<0.001$ & $42.9 \pm 4.9$ & $\mathrm{P}<0.001$ \\
\hline FPG(mg/dl) & $80.8 \pm 8.6$ & $134.1 \pm 12.4$ & $\mathrm{P}<0.001$ & $148.2 \pm 18.6$ & $\mathrm{P}<0.001$ \\
\hline $\begin{array}{l}\text { BP(mmHg) } \\
\text { Systolic } \\
\text { Diastolic }\end{array}$ & $117 \pm 4.9$ & $131.1 \pm 7.8$ & $\mathrm{P}<0.001$ & $122.4 \pm 7.9$ & $\mathrm{P}<0.05$ \\
\hline TAG(mg/dl) & $12.3 \pm 4.48$ & $86.6 \pm 4.8$ & $\mathrm{P}<0.001$ & $79.97 \pm 7.7$ & $\mathrm{P}<0.1$ \\
\hline $\begin{array}{l}\text { HDL-C } \\
\text { mg/dl }\end{array}$ & $47.1 \pm 5.6$ & $34.2 \pm 5.3$ & $\mathrm{P}<0.001$ & $30.1 \pm 3.3$ & $\mathrm{P}<0.001$ \\
\hline
\end{tabular}


TABLE 2: Parameters of liver function in the patients of NASH and cirrhosis compared with healthy controls.

\begin{tabular}{|l|l|l|l|l|l|}
\hline & $\begin{array}{l}\text { Controls } \\
\text { mean } \pm \text { S.D }\end{array}$ & $\begin{array}{l}\text { NASH } \\
\text { mean } \pm \text { S.D }\end{array}$ & $\begin{array}{l}\text { P value } \\
\text { (controls vs } \\
\text { NASH) }\end{array}$ & $\begin{array}{l}\text { Cirrhosis } \\
\text { mean } \pm \text { S.D }\end{array}$ & $\begin{array}{l}\text { P value } \\
\text { (controls vs } \\
\text { cirrhosis) }\end{array}$ \\
\hline TBil(mg/dl) & $0.5 \pm 0.2$ & $4.3 \pm 1.1$ & $\mathrm{P}<0.001$ & $4.7 \pm 0.8$ & $\mathrm{P}<0.001$ \\
\hline ALT(U/L) & $20.8 \pm 2.83$ & $163 \pm 18.2$ & $\mathrm{P}<0.001$ & $59.4 \pm 7.9$ & $\mathrm{P}<0.001$ \\
\hline ALP(U/L) & $78.94 \pm 21.7$ & $164.8 \pm 22.8$ & $\mathrm{P}<0.001$ & $155.7 \pm 19.7$ & $\mathrm{P}<0.001$ \\
\hline TPro(gm/dl) & $6.97 \pm 0.24$ & $6.8 \pm 0.35$ & $\mathrm{P}<0.1$ & $5.7 \pm 0.1$ & $\mathrm{P}<0.001$ \\
\hline Alb(gm/dl) & $4.45 \pm 0.2$ & $4.09 \pm 0.4$ & $\mathrm{P}<0.01$ & $2.7 \pm 0.18$ & $\mathrm{P}<0.001$ \\
\hline $\begin{array}{l}\text { Globulins } \\
\text { (gm/dl) }\end{array}$ & $2.5 \pm 0.13$ & $2.69 \pm 0.19$ & $\mathrm{P}<0.01$ & $2.99 \pm 0.21$ & $\mathrm{P}<0.001$ \\
\hline
\end{tabular}

Note: WC-waist circumference, BP- blood pressure, T Pro-total proteins, Alb-albumin, T Bil-total bilirubin 